Quim. Nova, Vol. 37, No. 1, 168-170, 2014

\title{
NANOPOROUS MATERIALS: PILLARED CLAYS AND REGULAR SILICAS AS AN EXAMPLE OF SYNTHESIS AND THEIR POROSITY CHARACTERIZATION BY X-RAY DIFFRACTION
}

\author{
João Pires \\ Departamento de Química e Bioquímica, Faculdade de Ciências, Universidade de Lisboa, Ed. C8, Campo Grande, 1749-016 \\ Lisboa, Portugal \\ Recebido em 04/03/2013; aceito em 17/07/2013; publicado na web em 02/09/2013

\begin{abstract}
Because of their practical applications, porous materials attract the attention of undergraduate students in a way that can be used to teach techniques and concepts in various chemistry disciplines. Porous materials are studied in various chemistry disciplines, including inorganic, organic, and physical chemistry. In this work, the syntheses of a microporous material and a mesoporous material are presented. The porosity of the synthesized materials is characterized by X-ray diffraction analysis. We show that this technique can be used to determine the pore dimensions of the synthesized materials.
\end{abstract}

Keywords: nanoporous materials; X-ray diffraction; lab experiment.

\section{INTRODUCTION}

Nanoporous materials, i.e., materials with pore widths between 1 and $100 \mathrm{~nm}$, have a wide range of effective and potential applications in fields such as catalysis, separation/purification, electronics, and drug delivery. ${ }^{1-3}$ The term "nanoporous" is relatively recent; in fact, the International Union of Pure and Applied Chemistry (IUPAC) classifies porous materials, according to their pore widths, as microporous (pore widths less than $2 \mathrm{~nm}$ ), mesoporous (pore widths between 2 and $50 \mathrm{~nm}$ ), and macroporous (pore widths greater than $50 \mathrm{~nm}){ }^{2,4}$ A large number of applications of nanoporous materials can be readily exemplified and understood, which usually attracts students' attention. Therefore, these types of solids can be used as a route to introduce undergraduate students to or to deeply explore various aspects of chemistry, particularly in the fields of inorganic and physical chemistry. In the experiments described in this text, X-ray diffraction (XRD) is used to characterize the porous structures of two types of materials obtained using two different synthetic approaches: the intercalation of a natural clay to produce a microporous material and a micelle-templated synthesis to obtain a mesoporous material.

Pillared interlayered clays (PILCs) are a relatively recent family of microporous materials. ${ }^{5}$ Students find the study of PILCs interesting because these solids are produced from natural clays,,${ }^{6,7}$ and their preparation is therefore an example of adding value to a natural product. Natural clays are layered solids but do not have definite porosity because they reversibly swell in the presence of water and a number of other molecules. ${ }^{6}$ Clays exhibit ion-exchange capabilities; therefore, PILCs are prepared by exchanging the charge-compensating cations present in the interlamellar space of clays with large hydroxy-metal polycations. After heating the PILCs, the inserted polycations yield rigid, thermally stable oxide species, which prop the clay layers apart and prevent their collapse. ${ }^{5}$ Figure 1 presents the main steps involved in the preparation of PILCs. A wide range of polyoxocations can be used as pillaring agents, but the most extensively studied polyoxocations are those of aluminum and zirconium..$^{5,8}$

The so-called ordered mesoporous materials include micelle-templated materials, which are an interesting group of nanoporous solids; these materials usually consist of silica pore walls formed around organic micelles, which are often long-chain quaternary ammonium

*e-mail: jpsilva@fc.ul.pt

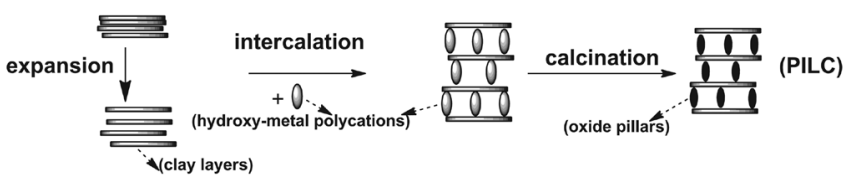

Figure 1. Main steps of the pillaring process

ions that act as a mold for the structure. The first materials of this type were reported in $1969,{ }^{9}$ but it was only in 1992 after a similar material was obtained by scientists in Mobil Oil Corporation ${ }^{10}$ that the properties of such materials gained recognition. ${ }^{11}$ The MCM-41 solid, in particular, shows a highly ordered hexagonal array of one-dimensional pores with walls made of amorphous silica. ${ }^{12}$

From a more specific view, the work described here exemplifies how a porous material can be obtained from entirely synthetic products or from a natural product, such a clay, and explores the technique of X-ray diffraction for the characterization of pore sizes. In a more general sense, the described experiments, while involving relatively simple methodologies, are expected to contribute to the students' general skills with respect to materials preparation and to stress to students, using the example of porous materials, the interdisciplinary nature of some basic concepts of various disciplines of chemistry. This approach therefore counters the belief of a large number of students that chemistry disciplines are well segmented.

\section{EXPERIMENTAL OVERVIEW}

\section{Pillared clay}

Many natural clays can be used as raw materials for this synthesis, provided that they contain smectite (expandable) clays, particularly montmorillonite, as a major fraction. Bentonites, such as Volclay SPV-200 from Ward's National Science Est., satisfy this requirement. Particularly interesting and of high pedagogical value is the case in which your university has a geology department that can provide a few grams of a local smectite clay. In this activity, a Zr-PILC is prepared because the preparation $\mathrm{Zr}$-polyoxocations is experimentally simple as they can be readily obtained from an aqueous solution of zirconium oxychloride $\left(\mathrm{ZrOCl}_{2} \cdot 8 \mathrm{H}_{2} \mathrm{O}\right)^{13}$ (Figure 2). Experimental and time-management details are given in the Supplementary Material.

$\mathrm{X}$-ray diffractograms are obtained to investigate the physical 


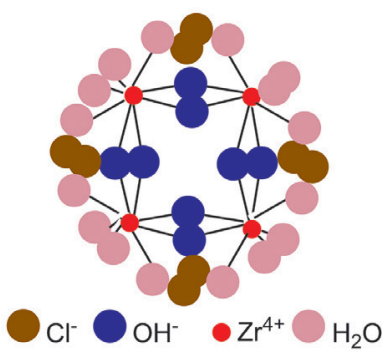

Figure 2. Model of the tetramer of zirconium cations (adapted from ref. 16)

changes that occur in the space between the clay layers during the pillaring process, i.e., the changes in the $d_{001}$ basal spacing (Figure 3 ). Sample diffractograms obtained by students are shown in Figure 4.

\section{MCM-41}

Tetraethyl orthosilicate (TEOS) is the most common silica source used in the synthesis of MCM-41-type materials, although various templating micelles can be used. ${ }^{11,14}$ These micelles are obtained from cationic organic surfactants such as cetyltrimethylammonium bromide, $\mathrm{H}_{3} \mathrm{C}\left(\mathrm{CH}_{2}\right)_{15} \mathrm{~N}\left(\mathrm{CH}_{3}\right)_{3} \mathrm{Br}(\mathrm{CTAB})$. In the present activity, in addition to $\mathrm{CTAB}$, tributylheptylammonium bromide $\left(\mathrm{H}_{3} \mathrm{C}\left(\mathrm{CH}_{2}\right)_{6} \mathrm{~N}\left(\mathrm{CH}_{2} \mathrm{CH}_{2} \mathrm{CH}_{2} \mathrm{CH}_{3}\right)_{3} \mathrm{Br}\right)$ was also used. In this way, the students can observe the effect of the template on the pore size. These two surfactants are structurally different because, in the latter case, the main chain is shorter $\left(\mathrm{C}_{7}\right.$ vs. $\mathrm{C}_{16}$ in $\left.\mathrm{CTAB}\right)$ and the remaining groups linked to the nitrogen atom are bulkier. Examples of the X-ray diffractograms obtained by students are shown in Figure 5 (and Figure 1S in the Supplementary Material). Experimental and time-management details for the preparation of both MCM-41 samples are given in the Supplementary Material.

\section{DISCUSSION}

The described experiments are appropriate for senior undergraduate students, particularly, but not exclusively, for those working on a mini-project basis in the areas of inorganic chemistry and materials chemistry or those enrolled in laboratory classes where the interdisciplinary nature of these disciplines is valued. The reagents are affordable, and the methodologies used allow the students to work with a considerable degree of autonomy, which may lead them to propose extensions of the work.

The first level of characterization of the prepared materials is conducted using XRD. An example of the discussion of the results for Zr-PILC in Figure 4 is presented in the Supplementary Material. In summary, starting from a natural clay, which has no fixed pore dimension because the $d_{001}$ value depends, in this case, even on the humidity, a microporous material with a fixed porosity value was obtained. Notably, although the synthesis of other types of microporous materials have been proposed for laboratory activities, such as the synthesis of zeolites,${ }^{15}$ information on pore dimensions obtained from XRD results cannot be obtained and analyzed by undergraduate students as readily as in the case of pillared clays.

Diffractograms of the MCM-41-type materials are given in Figure 5. Students synthesized the materials and obtained the diffractograms.

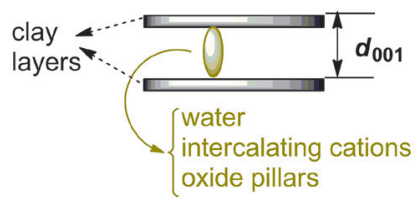

Figure 3. Schematic representation of the $d_{001}$ basal spacing in smectites

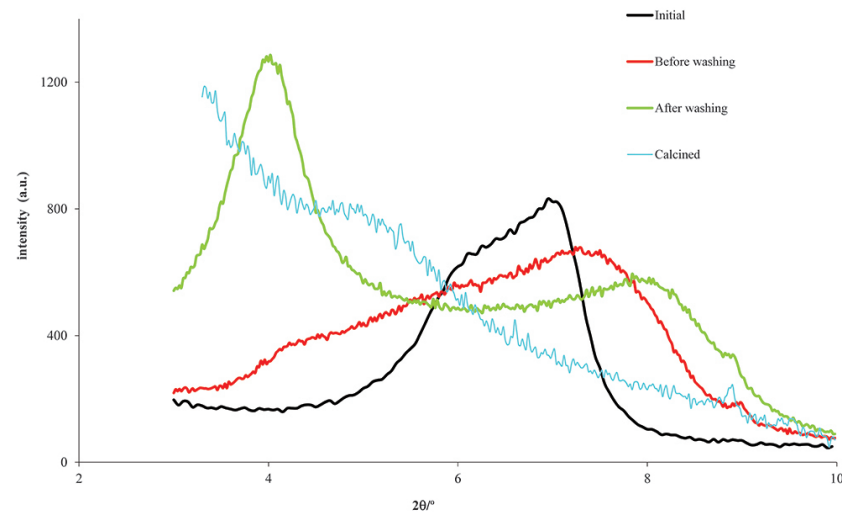

Figure 4. $X$-ray diffractograms in the $2 \theta$ region ascribed to $d_{001}$ for an initial clay and the samples in various phases of the pillaring process

Students should note that because of the large $d$ spacing and sometimes low degree of regularity in mesoporous materials compared to solids that can be obtained as single-crystals, only a few peaks are often observed in the XRD patterns of MCM-type solids. A more detailed discussion is presented in the Supplementary Material. The values listed in Table 1 are within the range of those presented in the literature for MCM-41-type materials. ${ }^{12}$ Although the silicates that form the walls of MCM-41 partially condensate at room temperature, the calcination step is mandatory to complete this condensation and avoid structural collapse. The values of the cell parameter $a_{0}$ listed in Table 1 show the calcination effect. The $a_{0}$ values decrease after calcination, i.e., upon the completion of the silicate condensation, and this effect is more evident in the case where only CTAB was used in the synthesis. When tributylheptylammonium bromide was used in addition to $\mathrm{CTAB}$, an increase in the unit cell parameter, i.e., an increase in the pore size, was observed.

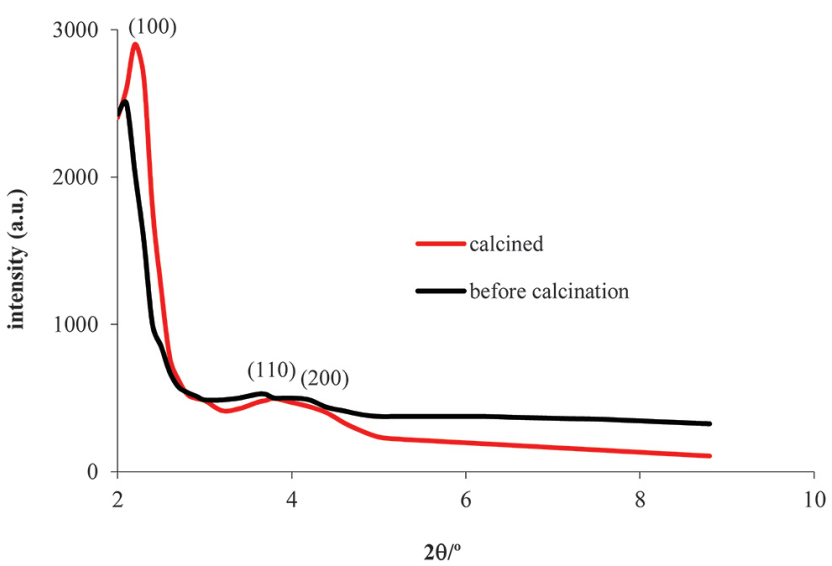

Figure 5. X-ray diffractogram for the MCM-41 sample, which was prepared using a mixture of CTAB and tributylheptylammonium bromide, before and after calcination

Table 1. Values of $d_{001}$ and $a_{0}$ for the mesoporous materials prepared with CTAB (A) and a mixture of CTAB and tributylheptylammonium bromide (B). The labels "before" and "after" are with respect to the calcination step

\begin{tabular}{ccc}
\hline Material & $d_{001} / \mathrm{nm}$ & $a_{0} / \mathrm{nm}$ \\
\hline (A) before & 4.07 & 4.70 \\
(A) after & 3.78 & 4.36 \\
(B) before & 4.15 & 4.79 \\
(B) after & 4.11 & 4.75 \\
\hline
\end{tabular}




\section{CONCLUSIONS}

The work presented here uses a relatively simple experimental approach for the preparation and characterization of nanoporous materials. This approach allows students of chemistry or other courses that involve materials chemistry to engage in material synthesis and to characterize by X-ray diffraction the samples they have synthesized. This experiment provides students the opportunity to apply learned competencies that are interdisciplinary. In addition, because of the perception of students that nanoporous materials have applications in a wide range of fields, students view the work favorably, which may contribute to the decision of some students to proceed with the theme of nanoporous materials in the final project of their bachelor or master course.

\section{SUPPLEMENTARY MATERIAL}

Supplementary material is freely available at http://quimicanova. sbq.org.br in the form of a PDF file. This material includes detailed experimental instructions, guidelines for synthesis, characterization, and time management, and complementary activities.

\section{ACKNOWLEDGMENT}

J. Pires is grateful to the CQB (strategic projects PEst-OE/QUI/ UI0612/2013) and the Department of Chemistry and Biochemistry, University of Lisbon, for resources.

\section{REFERENCES}

1. Lu, G. Q.; Zhao, X. S.; in Nanoporous Materials: Science and Engineering; Lu, G. Q.; Zhao, X. S., eds.; Imperial College Press: London, 2004, cap. 1.
2. Polarz, S.; Smarsly, B.; J. Nanosci. Nanotechnol. 2002, 2, 581.

3. Wang, S.; Microporous Mesoporous Mater. 2009, 117, 1.

4. Sing, K. S. W.; Everett, D. H.; Haul, R. A. W.; Moscou, L.; Pierotti, R. A.; Rouquerol, J.; Siemieniewska, T.; Pure Appl. Chem. 1985, 57, 603.

5. Gil, A.; Korili, A.; Trujillano, R.; Vicente, M. A.; Pillared Clays and Related Catalysts, Springer: New York, 2010; Gil, A.; Korili, A.; Vicente, M. A.; Catal. Rev. Sci. Eng. 2008, 50, 153.

6. Velde, B.; Introduction to Clay Minerals - Chemistry, Origins, Uses and Environmental Significance, Chapman \& Hall: London, 1992.

7. Grim, R. E.; Clay Mineralogy, $2^{\text {nd }}$ ed.; McGraw-Hill: New York, 1968.

8. Suzuki, K.; Horio, M.; Masuda, H.; Mori, T.; Bull. Chem. Soc. Jpn. 1991, 64, 732 .

9. Di Renzo, F.; Cambon, H.; Dutartre, R.; Microporous Mater. 1997, 10, 283.

10. Beck, J. S.; Vartuli, J. C.; Roth, W. J.; Leonowicz, M. E.; Kresge, C. T.; Schmitt, K. D.; Chu, C. T. W.; Olson, D. H.; Sheppard, E. W.; McMullen, S. B.; Shepard E. W.; J. Am. Chem. Soc. 1992, 114, 10834.

11. Taguchi, A.; Schüth, F.; Microporous Mesoporous Mater. 2005, 77, 1.

12. McCullen, S. B.; Vartuli, J. C.; Kresge, C. T.; Roth, W. J.; Beck, J. S.; Schmitt, K. D.; Leonowicz, M. E.; Schlenker, J. L.; Shih, S. S.; Lutner, J. D. In Access in Nanoporous Materials; Pinnavaia, T. J.; Thorpe, M. F., eds.; Plenum Press: New York, 1995.

13. Pereira, P. R.; Pires, J.; Carvalho M. B.; Langmuir 1998, 14, 4584; Figueras, F.; Mattrod-Bashi, A.; Fetter, G.; Thrierr, A.; Zanchetta, J. V.; J. Catal. 1989, 119, 91.

14. Hu, J.; Yin, J.; Lin, T.; Li, G.; J. Chem. Educ. 2012, 89, 284.

15. Copperthwaite, R. G.; Hutchlngs, G. J.; van der Rlet, M.; J. Chem. Educ. 1986, 63, 632; Blalier, F.; Schumacher, E.; J. Chem. Educ. 1990, 67, 519; Balkus, K. J.; Ly, K. T.; J. Chem. Educ. 1991, 68, 875; Belver, C.; Vicente, M. A.; J. Chem. Educ. 2006, 83, 1541.

16. Ohtsuka, K.; Hayashi, Y.; Suda, M.; Chem. Mater. 1993, 5, 1823; Muha, G.; Vaughan, P. A.; J. Chem. Phys. 1960, 33, 194. 


\section{NANOPOROUS MATERIALS: PILLARED CLAYS AND REGULAR SILICAS AS AN EXAMPLE OF SYNTHESIS AND THEIR POROSITY CHARACTERIZATION BY X-RAY DIFFRACTION}

\section{João Pires}

Departamento de Química e Bioquímica, Faculdade de Ciências, Universidade de Lisboa, Ed. C8, Campo Grande, 1749-016 Lisboa, Portugal

\section{STUDENT'S INFORMATION}

\section{General Remarks}

An experimental procedure to the synthesis of Zr-PILC and MCM-41 samples is given in the following, where reagents and material are described also. A proposal for time managing is presented.

\section{Experimental Instructions}

\section{Zr-PILC synthesis}

Two grams of a montmorillonite rich clay (for instance Bentonite CAS-No-1302-78-9) in $200 \mathrm{~mL}$ of water are stirred for a minimum of 2 hours, but preferably overnight. $50 \mathrm{~mL}$ of an aqueous 0.1 $\mathrm{mol} / \mathrm{L}$ Zirconium(IV) oxychloride octahydrate $\left(\mathrm{ZrOCl}_{2} \cdot 8 \mathrm{H}_{2} \mathrm{O}\right.$; CAS-No-13520-92-8) solution are then dropwise added to the clay dispersion (an isobaric dropping funnel can be used) under strong stirring. The mixture is then aged for 2 hours at $40{ }^{\circ} \mathrm{C}$ without stirring but under reflux, after which the solid phase is separated by centrifugation. Remove a small amount of solid for X-ray (the "Before washing" sample). Insert the solid in a dialysis tubing (example: cellulose membrane for retaining proteins of molecular weight 12000 or greater) that was previously boiled, close both sides of the tube and insert it in a container with distilled water (at least $500 \mathrm{~mL}$ ). Keep in water preferably during a week and, occasionally, change with new water. After this time open the dialysis tube, remove the slurry and evaporate the water (use a rotary evaporator, but do not set the temperature above $60^{\circ} \mathrm{C}$ ). Remove a small amount of solid for X-ray (the "After washing" sample). Dry at $90-100^{\circ} \mathrm{C}$, put the solid in an alumina boat and calcined at $350^{\circ} \mathrm{C}$ for $2-3$ hours preferably in a open tubular oven or other type of oven that allows some degree of air to enter in it.

\section{MCM-41 synthesis}

Weight $2.642 \mathrm{~g}$ of hexadecyltrimethylammonium bromide - CTAB (CAS-No-57-09-0) and add $132 \mathrm{~mL}$ of distilled water. Stir (magnetic stirring) under gentle heating until the solution becomes colourless (approximately 30 minutes). Add $11.2 \mathrm{~mL}$ of ammonium hydroxide solution $(25 \% \mathrm{w} / \mathrm{w})$, keep stirring for 2-3 minutes, add $11.4 \mathrm{~mL}$ of tetraethyl orthosilicate - TEOS (CAS-No-78-10-4) and maintain the stirring for 2.5 hours. Filter, wash with water preferably until the $\mathrm{pH}$ becomes neutral (use vacuum filtration with Büchner funnel), and dry at $90{ }^{\circ} \mathrm{C}$ until next laboratory session. Keep at least an adequate portion of the uncalcined form to obtain the X-ray diffractogram, and put the remaining solid in an alumina boat and calcined at $550{ }^{\circ} \mathrm{C}$ for 5 hours preferably in a open tubular oven or other type of oven that allows some degree of air to enter in it. For the synthesis with the mixture of hexadecyltrimethylammonium and tributylheptylamonium bromide (CAS-No-85169-31-9) the same methodology is to be used but mix $1.984 \mathrm{~g}$ of the former and $0.657 \mathrm{~g}$ of the latter.

*e-mail: jpsilva@fc.ul.pt

\section{Hazards}

Tetraethyl orthosilicate - TEOS (CAS-No-78-10-4) is flammable, may cause irritation to eyes an skin and its long-term exposure may cause kidney or liver damage.

Ammonium hydroxide solution (CAS-No-1336-21-6) is corrosive, causes severe skin burns and eye damage.

Hexadecyltrimethylammonium bromide (CASNo-57-09-0) presents acute toxicity, it causes oral skin irritation and serious eye damage and it may cause respiratory irritation.

Zirconium(IV) oxychloride octahydrate (CAS-No-13520-92-8) may causes severe skin burns and eye damage.

Tributilheptaamonium bromide (CAS-No-85169-31-9) is irritant to eyes and respiratory system and skin.

Clays (for instance Bentonite CAS-No-1302-78-9) are hazardous in case of eye contact (irritant), and of inhalation. They are slightly hazardous in case of skin contact (irritant), and of ingestion. Avoid dust formation.

Always wear suitable protective clothing, gloves and eye/face protection.

Environmental regulations should be followed for the disposal of waste.

The calcination step needs special attention and students should be advised not to remove the sample from the furnace before it cools to a temperature near ambient.

\section{Characterization by X-ray diffraction}

$\mathrm{X}$-ray diffractograms are to be obtained between $2 \theta$ degrees of 2 and 10 , since this is the region where the signals for the $d_{001}$ appear for clays ${ }^{\mathrm{S1}, \mathrm{S} 2}$ and where the relevant information for MCM-41 is obtained also. In this way the X-ray apparatus can be programmed with the appropriated time per step so each diffractogram will take less than 20 minutes to obtain. Typical (for a Philips XRD model PW3710) time per step and step size are $2.5 \mathrm{~s}$ and 0.02 degrees, respectively.

X-ray difractograms for the MCM-41 samples can be obtained by the usual powder method, just by deposing it in the appropriated support and compacting gently the powder. The same for the initial clay if the presence of other minerals is to be studied, cf. Figure S5, but, in this case the $2 \theta$ degrees range to be used is from 3 to 50 . For the Zr-PILC samples, and to have more accuracy in the $d_{001}$ values, oriented mounts should be used. For this a slurry (clay plus water) is to be prepared by initially dispersing the clay in water by stirring or, preferably, by using a ultrasonic bath so the clay particles will be more efficiently dissociated. Then the slurry is concentrated, for instance by centrifugation, deposit in a glass slide (that fits the X-ray in the apparatus) and let to dry at ambient or in a oven at moderate temperature (below $50{ }^{\circ} \mathrm{C}$ ). As alternative to the centrifugation, the slurry may settle and a small portion can be transferred with a Pasteur pipette to the glass slide and let to dry. Repeat the transfer/dry two or three times. Making oriented mounts is detailed described in the reference $\mathrm{S} 1$. 


\section{TIME MANAGEMENT}

\section{Laboratory sessions of 3 to 4 hours were considered.}

Zr-PILC

First session: the theme is presented to the students, and they get acquainted with related bibliography but they also need to prepare the $0.1 \mathrm{M} \mathrm{ZrOCl}_{2} \cdot 8 \mathrm{H}_{2} \mathrm{O}$ solution and the clay dispersion in water. Preferable, the X-ray diffractogram of the initial material should be obtained also.

Second session: the pillaring process is to be made and the pillared material is left washing in the dialysis tube until the next session (preferably a week latter). Glass slide for XRD of the "Before washing" sample can be prepared

Third session: calcination of the intercalated material. X-ray difractograms of previous samples and preparation of the glass slide of the calcined material.

If only three working sessions are to be used, the X-ray diffractogram of the calcined sample may be obtained in student free time or the instructor may provide it since the students already made the experiment with other samples. If a fourth session is available the $\mathrm{X}$-ray diffractogram of the calcined sample can then be obtained and the remaining time used to analyse the results and make a previous discussion of them with the instructor.

\section{$M C M-41$}

First session: presentation of the theme to the students, and get acquainted with related bibliography but, preferably, they should start the synthesis of the sample prepared with CTAB and use the 2.5 hours of stirring time to start search and reading literature. Non-calcined sample is obtained.

Second session: calcination of the material from the first synthesis and making the second synthesis (with the second template). Since the calcination will need 5 hours, plus some time to become to a temperature where it may be removed from the oven, there are mainly two options. The students (with the instructor) may use some free time before the class just to put the alumina boat in the oven and start the calcination, so it will be ready by the end of the session or the calcination would need to be started by the instructor. During the 2.5 hours of stirring time, students may progress in the literature study or they can obtain the X-ray diffractogram of the non-calcined sample from the previous session.

Third session: calcination of the material from the second synthesis. X-ray diffractograms (calcined sample from the first synthesis

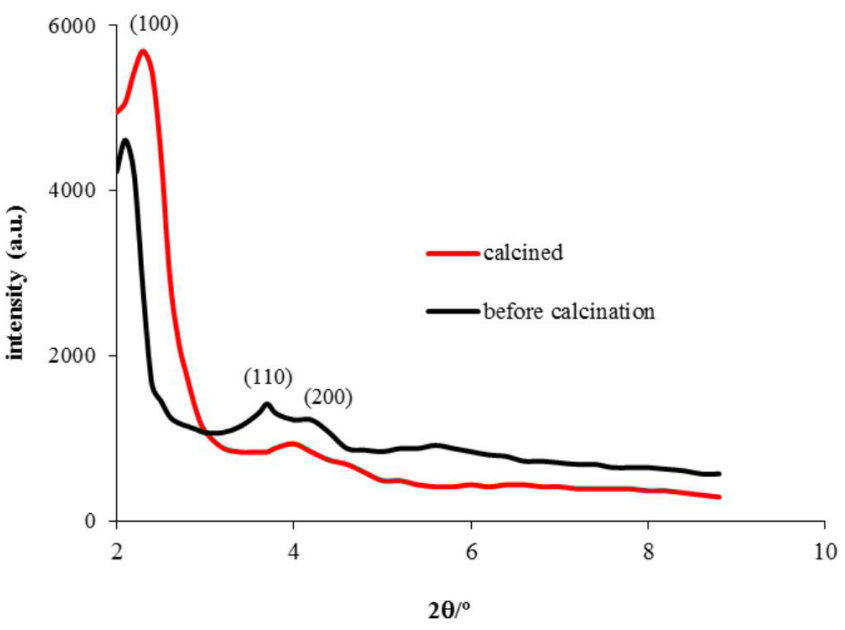

Figure 1S. X-ray diffractogram for the MCM-41 sample, prepared with cetyltrimethylammonium bromide, before and after calcination

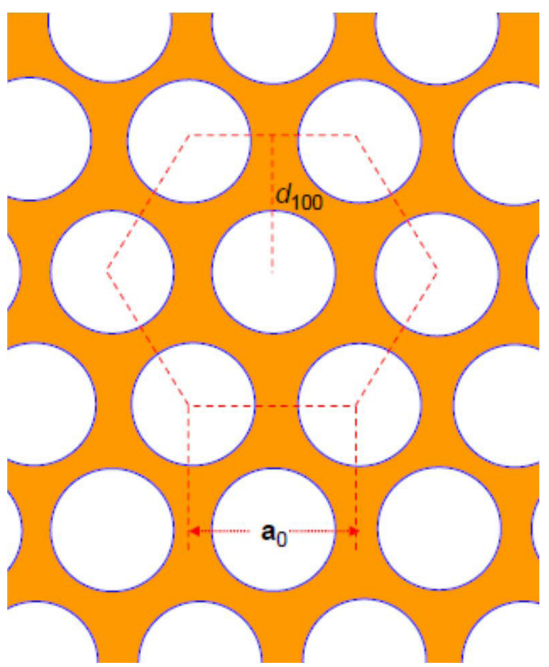

Figure 2S. Structure of the MCM-41 material (a transversal plan) with its hexagonal array of pores and the corresponding $\boldsymbol{a}_{0}$ cell parameter

and non calcined sample from the second synthesis). Analysis of the diffractogram to obtain the cell parameter.

If only three working sessions are to be used the last X-ray diffractogram of the calcined sample from the second synthesis maybe obtained in student free time or the instructor may provide it since the students already made the experiment with other samples. If a fourth session is available the X-ray data can analysed and IR spectroscopy (in $\mathrm{KBr}$ wafers) can be used, at least for the samples before and after calcination of one of the synthesis. IR spectroscopy analysis can be made by the indexation of the major bands from the $\mathrm{SiO}_{2}$ moiety, $1300-1000 \mathrm{~cm}^{-1}$ and near $800 \mathrm{~cm}^{-1}$ and also to show the removal of the organic alkyl ammonium template by comparing the spectra in the range $2850-3000 \mathrm{~cm}^{-1}$ where the organic part will absorb.

\section{NOTES FOR THE INSTRUCTOR}

\section{Discussion}

\section{PILCs}

In the case of the initial clay, the maximum of the diffraction peak is for $2 \theta$ of $7.09^{\circ}$, giving a value for the basal spacing $\left(d_{001}\right)$ of 1.25 $\mathrm{nm}$. This value is calculated from the basic equation of the Bragg law, defined as $\mathrm{n} \lambda=2 d \sin \theta$, where, $\mathrm{n}$ is an integer number - the diffraction order, $d$ is the distance between the planes, $\theta$ is the Bragg angle and $\lambda$ is the wavelength of the $\mathrm{X}$-ray (commonly from a Copper $\mathrm{K} \alpha \mathrm{X}$-ray source with $\lambda=0.15418 \mathrm{~nm}$ ). Students may note that the diffraction peaks for the natural clays are often broad, relatively to other minerals such as quartz for instance. This is because clays may present some variation in their chemical composition and also in the crystal sizes. The obtained $d_{001}$ value is within the range ascribed to montmorillonite type clays. ${ }^{\mathrm{S}, \mathrm{S} 2}$ After the intercalation with the $\mathrm{Zr}$ polyoxocations started (the "Before washing" sample) the diffraction peak became broader as a result of the still incomplete intercalation process. After the washing process two peaks are noticed, both due to $d_{001}$ reflections. The peak for the lowest $2 \theta$ values ( $d_{001}$ of 1.93 $\mathrm{nm}$ ) can be ascribed to the intercalated clay and the peak to higher $2 \theta$ values can be attributed to a portion of clay that was in fact nonintercalated, a situation that was already reported in the literature. ${ }^{\mathrm{S} 3}$ During calcination the $\mathrm{Zr}$-polyoxocations dehydroxylate to form the oxide and that is why the $d_{001}$ value of the final sample $(1.70 \mathrm{~nm})$ is lower than for the samples before calcination. To obtain the gallery heights of the pores, the dimensions of the clay layers, ${ }^{\mathrm{S} 3} 0.96 \mathrm{~nm}$, needs to be subtracted from the $d_{001}$ value, giving $0.74 \mathrm{~nm}$. 


\section{MCM-41 materials}

Typically, MCM-41 exhibits an XRD pattern with three or more diffraction lines which can be indexed to a hexagonal lattice as a result of the regular, hexagonal array of uniform channels. ${ }^{54}$ For an hexagonal lattice the relation between the unit cell parameter $\left(a_{0}\right)$ and the $d_{100}$ obtained from the X-ray diffraction pattern is ${ }^{\mathrm{S} 4 \mathrm{~S} 5}$ $a_{0}=2 d_{100} / \sqrt{3}$ as schematically presented in Figure $2 \mathrm{~S}$. Pore diameters can be estimated from the unit cell parameter $-a_{0}$, subtracting the thickness of the pore walls (cf. Figure 2S). Although some discussion exist in the literature about the thickness of the pore walls in MCM-41 type materials $\mathrm{s}^{\mathrm{S} 5}$ an average value of $1 \mathrm{~nm}$ for the calcined materials can be admitted. The values of $d_{001}$ and $a_{0}$ for the prepared samples, before and after calcination, are given in Table 1.

\section{Additional and complementary activities}

IR spectroscopy (in $\mathrm{KBr}$ wafers) can be used to study the MCM-41 samples for instance by the indexation of the major bands from the $\mathrm{SiO}_{2}$ moiety. Examples are the strong and broad absorbance band in the 1300-1000 $\mathrm{cm}^{-1}$ region assigned to the asymmetric stretching modes, $v_{\text {as }}(\mathrm{Si}-\mathrm{O}-\mathrm{Si})$, and the band near $800 \mathrm{~cm}^{-1}$ assigned to the symmetric stretching mode $v_{s}(\mathrm{Si}-\mathrm{O}-\mathrm{Si}) .{ }^{\mathrm{S} 6}$ Additionally, IR spectroscopy of the MCM-41 samples, before and after calcination, can also be used to show the removal of the organic alkyl ammonium template by comparing the spectra in the range $2850-3000 \mathrm{~cm}^{-1}$ where the organic part will absorb.

If nitrogen adsorption at $-196^{\circ} \mathrm{C}$ is available the characterization of porosity can be extended by the determination of the nitrogen adsorption isotherms and the evaluation of the specific surface areas and pore volumes of the materials. ${ }^{\mathrm{S7}}$ Typical nitrogen adsorption isotherms in a MCM-41 material and in a Zr-PILC are shown in Figure S4.

The prepared materials can be used for activities described in previous laboratory activities such as gas-chromatographic studies ${ }^{\mathrm{S8}}$ or the adsorption of water pollutants for environmental applications. ${ }^{S 9, \$ 10}$ Both, the Zr-PILC and the MCM-41 can be used to illustrate the possibilities of porous materials as catalyst supports. For this, an inorganic complex that the students may have previously prepared, for instance in their laboratories of Inorganic Chemistry, such as a
$\left[\mathrm{Cu}(\mathrm{acac})_{2}\right],\left[\mathrm{Fe}(\mathrm{acac})_{3}\right]$, Ferrocene, etc., can be selected. Various methodologies of introducing inorganic complexes in porous solids are described in the literature and can easily be adapted, with the possibilities of the characterization of the unsupported and supported complexes by spectroscopic techniques. ${ }^{\text {S11 }}$

The X-ray diffractogram of the parent clay can be used to illustrate the systematic use of the ICDD (International Center for Diffraction Data) files in the identification of the minerals when these occur in a mixture. An example is in Figure $4 \mathrm{~S}$.

\section{REFERENCES}

S1. Velde, B.; Introduction to Clay Minerals - Chemistry, Origins, Uses and Environmental Significance, Chapman \& Hall: London, 1992.

S2. Grim, R. E.; Clay Mineralogy, 2nd ed.; McGraw-Hill: New York, 1968.

S3. Suzuki, K.; Horio, M.; Masuda, H.; Mori, T.; Bull. Chem. Soc. Jpn. 1991, 64, 732 .

S4. McCullen, S. B.; Vartuli, J. C.; Kresge, C. T.; Roth, W. J.; Beck, J. S.; Schmitt, K. D.; Leonowicz, M. E.; Schlenker, J. L.; Shih, S. S.; Lutner, J. D. In Access in Nanoporous Materials; Pinnavaia, T. J.; Thorpe, M. F., eds.; Plenum Press: New York, 1995.

S5. Lu, A. H.; Zhao D.; Wan Y.; Nanocasting: A Versatile Strategy for Creating Nanostructured Porous Materials, Royal Society of Chemistry: Cambridge, 2010, chap. 1.

S6. Galeener, F. L.; Phys. Rev. B: Condens. Matter 1979, 19, 4292.

S7. Rouquerol, F.; Rouquerol, J.; Sing, K.; Adsorption by powders \& porous solids, Academic Press: London, 1999.

S8. Chao, P. Y.; Chuang, Y.-Y.; Ho, G. H.; Chuang, S.-H.; Tsa, T.-C.; Lee, C.-Y.; Tsai, S.-T.; Huang, J.-F.; J. Chem. Educ. 2008, 85, 1558.

S9. Lynam, M. M.; Kilduff, J. E.; Weber, W. J.; J. Chem. Educ. 1995, 72, 80.

S10. Oliveira, L. C. A.; Rios, R. V. R. A.; Fabris, J. D.; Lago, R. M.; Sapag, K.; J. Chem. Educ. 2004, 81, 248.

S11.Fraile, J. M.; Garcia, J. I.; Massam, J.; Mayoral, J. A.; J. Mol. Catal. A: Chem. 1998, 136, 47; Kureshy, R. I.; Khan, N. H.; Abdi, S. H. R.; Ahmad, I.; Singh, S.; Jasra, R. V.; J. Catal. 2004, 221, 234; Ogunwumi, S. B.; Bein, T.; J. Chem. Soc., Chem. Commun. 1997, 901; Cardoso, B.; Pires, J.; Carvalho, A. P.; Kuzniarska-Biernacka, I.; Silva, A. R.; Castro, B.; Freire, C.; Microporous Mesoporous Mater. 2005, 86, 295.

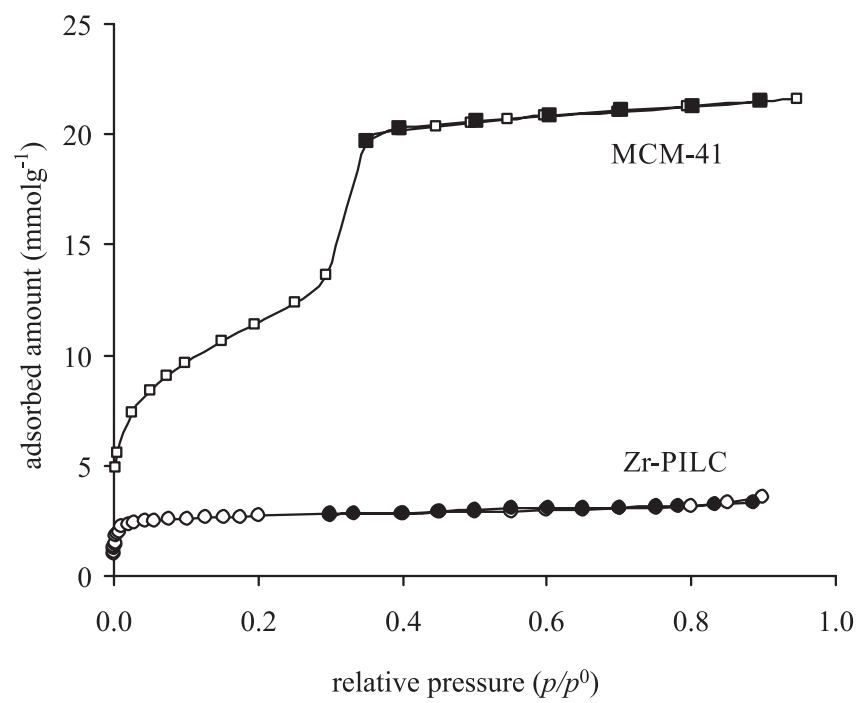

Figure 3S. Nitrogen adsorption isotherms in a mesoporous MCM-41 material and in a microporous Zr-PILC. (open points- adsorption; closed points - desorption) 


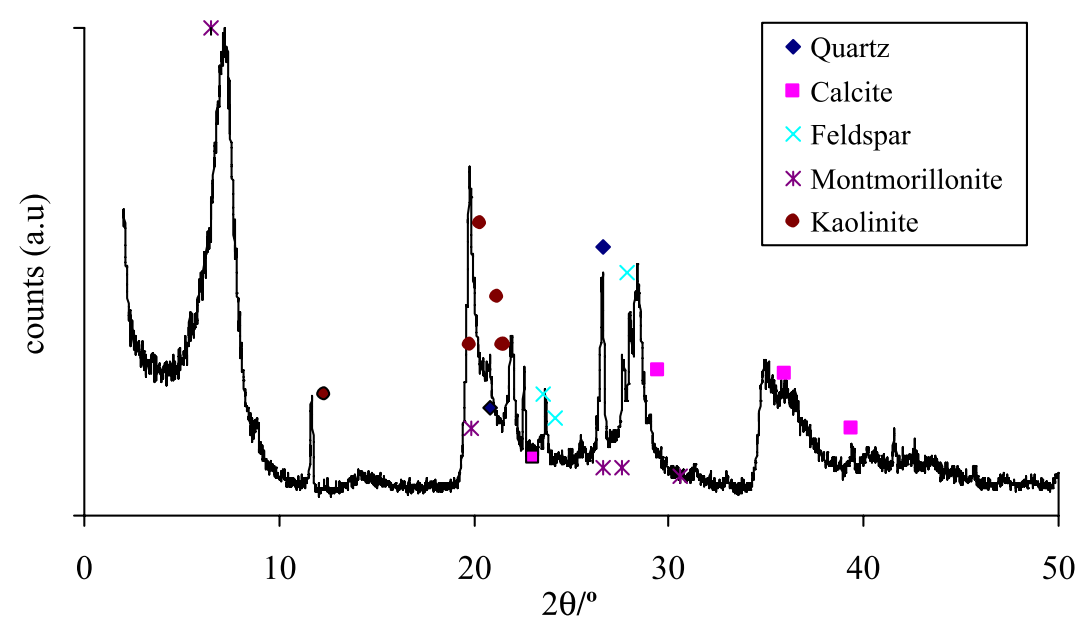

\begin{tabular}{|l|l|l|l|l|l|l|l|l|l|l|}
\hline \multicolumn{3}{|l|}{ Quartz } & \multicolumn{2}{l|}{ Feldspar } & \multicolumn{2}{l|}{ Calcite } & \multicolumn{2}{l|}{ Montmorillonite } & \multicolumn{2}{l|}{ Kaolinite } \\
\hline $39-1425$ & & $9-466$ & & $5-586$ & & $13-259$ & & $14-164$ & \\
\hline $2 \theta / \circ$ & $\begin{array}{l}\text { relative } \\
\text { intensity }\end{array}$ & $2 \theta /{ }^{\circ}$ & $\begin{array}{l}\text { relative } \\
\text { intensity }\end{array}$ & $2 \theta /{ }^{\circ}$ & $\begin{array}{l}\text { relative } \\
\text { intensity }\end{array}$ & $2 \theta /{ }^{\circ}$ & $\begin{array}{l}\text { relative } \\
\text { intensity }\end{array}$ & $2 \theta /{ }^{\circ}$ & $\begin{array}{l}\text { relative } \\
\text { intensity }\end{array}$ \\
\hline 20.85 & 22 & 27.89 & 100 & 23 & 12 & 6.494 & 100 & 12.335 & 100 \\
26.662 & 100 & 23.51 & 25 & 29.4 & 100 & 19.846 & 18 & 19.81 & 35 \\
36.852 & 8 & 24.13 & 20 & 35.97 & 14 & 26.668 & 10 & 20.324 & 60 \\
39.456 & 8 & 24.27 & 16 & 39.402 & 18 & 27.594 & 10 & 21.208 & 45 \\
50.141 & 14 & 25.36 & 10 & 43.176 & 18 & 30.591 & 8 & 21.5 & 35 \\
59.948 & 9 & 13.84 & 20 & 47.49 & 17 & & & 21.451 & 35 \\
68.323 & 8 & 22.03 & 16 & 48.513 & 17 & & & 24.858 & 80 \\
\hline
\end{tabular}

Figure 4S. Example of identification of some minerals that, in addition to montmorillonite, can by present in starting material. The Table includes the number of the respective ICDD powder diffraction files 